\title{
Gender, Productivity, and Philanthropic Fundraising in Academic Oncology
}

Subha Perni, MD ${ }^{1,2, *}$; Danielle Bitterman, $\mathrm{MD}^{1,2, *}$; Jennifer Ryan, BA²; Julie K. Silver, MD ${ }^{3,4}$; Eileen Mitchell, $\mathrm{BS}^{2}$; Sarah Christensen, MS, MBA ${ }^{5}$; Megan Daniels, BA²; Mara Bloom, JD, MS²; Ephraim Hochberg, MD²; David Ryan, MD²; Daphne Haas-Kogan, MD ${ }^{6}$; Jay S. Loeffler, MD²; Nancy J. Tarbell, MD²; Aparna R. Parikh, MD ${ }^{2, \dagger}$; and Jennifer Wo, MD ${ }^{2, \dagger}$

\section{ABSTRACT}

Background: Philanthropic donations are important funding sources in academic oncology but may be vulnerable to implicit or explicit biases toward women. However, the influence of gender on donations has not been assessed quantitatively. Methods: We queried a large academic cancer center's development database for donations over 10 years to the sundry funds of medical and radiation oncologists. Types of donations and total amounts for medical oncologists and radiation oncologists hired prior to April 1, 2018 (allowing $\geq 2$ years on faculty prior to query), were obtained. We also obtained publicly available data on physician/academic rank, gender, specialty, disease site, and Hirsch-index ( $h$-index), a metric of productivity. Results: We identified 127 physicians: $64 \%$ men and $36 \%$ women. Median $h$-index was higher for men (31; range, $1-100)$ than women (17; range, $3-77 ; P=.003)$. Men were also more likely to have spent more time at the institution (median, 15 years; range, 2-43 years) than women (median, 12.5 years; range, 3-22 years; $P=.025)$. Those receiving donations were significantly more likely to be men (70\% vs $30 \% ; P=.034)$. Men received significantly higher median amounts $(\$ 259,474$; range, $\$ 0-\$ 29,507,784)$ versus women $(\$ 37,485$; range, $\$ 0-\$ 7,483,726 ; P=.019)$. On multivariable analysis, only $h$-index and senior academic rank were associated with donation receipt, and only $h$-index with donation amount. Conclusions: We found significant gender disparities in receipt of philanthropic donations on unadjusted analyses. However, on multivariable analyses, only productivity and rank were significantly associated with donations, suggesting gender disparities in productivity and promotions may contribute to these differences.

J Nat/ Compr Canc Netw 2021;19(12):1401-1406 doi: $10.6004 /$ jnccn.2021.7008

\footnotetext{
${ }^{1}$ Harvard Radiation Oncology Program, ${ }^{2}$ Massachusetts General Hospital Cancer Center, ${ }^{3}$ Department of Physical Medicine and Rehabilitation, Massachusetts General Hospital, Brigham and Women's Hospital, and

${ }^{4}$ Spaulding Rehabilitation Hospital, Boston, Massachusetts; and ${ }^{5}$ University of Miami Health System, Miami, Florida; and ' Department of Radiation Oncology, Brigham and Women's Hospital and Dana-Farber Cancer Institute, Boston, Massachusetts.
}

*These authors are co-first authors.

tThese authors are co-last authors.

\section{Background}

Philanthropic donations (PDs) are an important source of funding in academic oncology, often substantially supplementing federal and industry support for biomedical research. ${ }^{1}$ Medical institutions typically employ trained development staff and encourage physicians to solicit PDs. Previous work has explored the ethical concerns that arise in PD solicitation, including conflicts of interest, fairness in patient treatment, and effects on physician-patient relationships. ${ }^{2-4}$ An additional concern is exacerbation of gender workforce disparities. Such disparities have been shown to exist for female physician-scientists in terms of federal grant funding, industry support, publications, medical promotions, leadership positions, and salaries. ${ }^{5-9}$

Philanthropic fundraising, in contrast to traditional private and public grant-based funding mechanisms, is less reliant on rigorous evaluation of scientific merit for determination of awards, and more reliant on interpersonal relationships and provider proactiveness in broaching opportunities. As such, philanthropy may be particularly vulnerable to implicit and explicit biases toward women. Among other factors, men may be more likely to be perceived as leaders, whereas women may face societal stereotypes about "pushiness" and caregiving. ${ }^{10}$

In a recent survey of oncologists, $71 \%$ reported having been exposed to fundraising or development staff. However, of the respondents, men were significantly more likely to feel comfortable talking to patients about PDs. At the same time, women were significantly more likely to believe that there would be negative consequences if they refused to participate in philanthropy. ${ }^{11}$

Although women report less comfort with soliciting PDs, to our knowledge, there have been no studies examining the influence of gender on receipt of PDs in academic oncology, and no prior evaluation of associations among donations, productivity, and physician/ academic rank. To better understand these relationships, we analyzed development records at a large academic cancer center, identifying factors associated with PD receipt and PD amount. 


\section{Methods}

We queried the internal institutional development office database at Massachusetts General Hospital Cancer Center for total amounts of philanthropic funds from the past 10 years as evaluated by PDs present in an individual medical or radiation oncologist principal investigator's sundry fund. Sundry funds can be used to support any research-related activity and could potentially be transferred from one individual to another. Types of donations, including individual, corporate/foundation, estate/trust, and miscellaneous, as well as total amounts in sundry funds for medical oncologists and radiation oncologists hired prior to April 1, 2018 (allowing $\geq 2$ years on faculty prior to query) were obtained. A few corporate donations were private grant funds requiring applications.

Publicly available data on academic rank, gender, specialty, and disease site were obtained from institutional websites. The Scopus database (www.scopus.com) was queried for Hirsch-index ( $h$-index), one academic productivity metric defined as number of publications $(h)$ cited at least $h$ times. $^{12}$

Statistical analyses were conducted using JMP 14 (SAS Institute Inc). Chi-square and Wilcoxon rank sum tests were used to compare categorical and continuous variables, respectively. Univariable and multivariable logistic regression analyses were used to explore factors associated with PD receipt, including gender, $h$-index, academic rank, and years at institution. Multivariable linear regression analyses were used to explore factors associated with received PD amount, which was modeled logarithmically to achieve a more approximately normal distribution. Statistical significance was set a priori at a 2-sided $\alpha$ of 0.05 .

Additionally, multivariable analyses were conducted for the subset of medical oncologists. Multivariable analyses were not conducted on the subset of radiation oncologists given the small numbers. Finally, to characterize the population of the most successful fundraisers, we conducted descriptive analyses of the top 10 fundraisers by gender.

\section{Results}

We identified 127 physicians, of which $64 \%$ were men and $36 \%$ were women; $82 \%$ were medical oncologists and $18 \%$ were radiation oncologists. The most common disease site focuses were hematologic (26\%), breast (16\%), and thoracic $(12 \%)$. Regarding academic rank, $41 \%$ were instructors, $24 \%$ were assistant professors, $15 \%$ were associate professors, and $20 \%$ were full professors. Median time at institution was 14 years (range, 2-43 years), and median $h$-index was 24 (range, 1-100).

Table 1 shows potential factors influencing PDs by gender. Specialty, disease site, and academic rank were not significantly different by gender. However, the median $h$-index of men was 31 (range, 1-100), which was

\begin{tabular}{|c|c|c|c|}
\hline & $\begin{array}{l}\text { Men } \\
\text { n (\%) }\end{array}$ & $\begin{array}{l}\text { Women } \\
\text { n (\%) }\end{array}$ & $P$ Value \\
\hline Total, n & 81 & 46 & \\
\hline Specialty & & & .424 \\
\hline Medical oncology & $68(84)$ & $36(78)$ & \\
\hline Radiation oncology & $13(16)$ & $10(22)$ & \\
\hline Academic rank & & & .082 \\
\hline Instructor & $27(33)$ & $25(54)$ & \\
\hline Assistant professor & $22(27)$ & $9(20)$ & \\
\hline Associate professor & $12(15)$ & $7(15)$ & \\
\hline Full professor & $20(25)$ & $5(11)$ & \\
\hline Years at institution & & & .025 \\
\hline Median (range) & $15(2-43)$ & $12.5(3-22)$ & \\
\hline$h$-index & & & .003 \\
\hline Median (range) & $31(1-100)$ & $17(3-77)$ & \\
\hline
\end{tabular}

Bold indicates statistically significant $P$ value.

significantly higher than that of women (17; range, 3-77; $P=.003$ ). Median $h$-index was 12.5 (range, $1-42$ ) for instructors, 31 (range, 12-44) for assistant professors, 34 (range, 1-72) for associate professors, and 67 (range, $6-100)$ for full professors $(P<.0001)$. Men were at the institution significantly longer (median, 15 years; range, 2-43 years) compared with women (median, 12.5 years; range, 3-22 years; $P=.025$ ).

Overall, there was $\$ 158,864,002.68$ in PDs over 10 years, distributed among 52,180 gifts. Most were from individuals $(91 \%)$; corporate foundations gave $7 \%$, estates and trusts $1 \%$, and miscellaneous sources $1 \%$. The median amount of PDs was $\$ 161,691.45$ (range, $\$ 0-\$ 29,507,783.50$ ).

Table 2 shows differences in characteristics of oncologists who received PDs versus those who did not. PD receipt was significantly associated with male gender and academic rank. Oncologists that received PDs were also significantly more likely to have been at the institution longer (median, 16 years [range, $2-42$ years] vs 9 years [range, 3-43 years]; $P<.001$ ). Median $h$-index was significantly higher among those that received PDs (median, 34 [range, $1-100$ ] vs 12 [range, 1-44]; $P<.001$ ).

As shown in Figure 1A and B, men overall had significantly higher median number of donations of every type, with significantly higher median total fundraising amount. Those receiving donations were significantly more likely to be men ( $70 \%$ vs $30 \%$; $P=.034$ ), and received significantly higher median amounts $(\$ 259,474.30$; range, $\$ 0-\$ 29,507,784)$ compared with women $(\$ 37,485$; range, $\$ 0-\$ 7,483,726 ; P=.019)$. In the subset that received donations $(n=84)$, gender did not correlate with total fundraising amount, but men received significantly more donations of every type (Figure 1C, D). 


\begin{tabular}{|c|c|c|c|}
\hline & $\begin{array}{l}0 \text { PDs } \\
\text { n (\%) }\end{array}$ & $\begin{array}{l}\geq 1 \text { PDs } \\
\text { n (\%) }\end{array}$ & $P$ Value \\
\hline Total, $n$ & 43 & 84 & \\
\hline Gender & & & .034 \\
\hline Men & $22(51)$ & $59(70)$ & \\
\hline Women & $21(49)$ & $25(30)$ & \\
\hline Specialty & & & .384 \\
\hline Medical oncology & $37(86)$ & $67(80)$ & \\
\hline Radiation oncology & $6(14)$ & $17(20)$ & \\
\hline Academic rank & & & $<.001$ \\
\hline Instructor & $35(81)$ & $17(20)$ & \\
\hline Assistant professor & $7(16)$ & $24(29)$ & \\
\hline Associate professor & $1(2)$ & $18(21)$ & \\
\hline Full professor & $0(0)$ & $25(30)$ & \\
\hline Years at institution & & & $<.001$ \\
\hline Median (range) & $9(3-43)$ & $16(2-42)$ & \\
\hline$h$-index & & & $<.001$ \\
\hline Median (range) & $12(1-44)$ & $34(1-100)$ & \\
\hline
\end{tabular}

Bold indicates statistically significant $P$ value.

Abbreviation: PDs, philanthropic donations.

On multivariable analysis, $h$-index was most strongly associated with PD receipt, followed by senior academic rank; gender and years at institution were not significant (Table 3). On multivariable analysis for total donation amount, $h$-index was the only significant covariate (Table 3 ).

We additionally analyzed the subset of medical oncologists. Among the 104 medical oncologists, there were no significant differences in PD receipt by gender: $71 \%$ of men and $53 \%$ of women received PDs $(P=.07)$. However, men had significantly higher median fundraising than women $(\$ 259,474.30$ [range, $\$ 0-\$ 29,507,784$ ] vs $\$ 30,020$ [range, $\$ 0-\$ 7,483,726$ ]; $P=.049$ ). On multivariable analysis, $h$-index and senior academic rank were significantly associated with PD receipt (Table 4 ), whereas only $h$-index was significantly associated with total donation amount (Table 4).

We finally analyzed the top 10 fundraisers for each gender. The top 10 women fundraisers raised a median of $\$ 2,087,911.88$ (range, $\$ 600,970.00-\$ 7,483,725.97$ ) over a median of 281 gifts (range, 13-7,409). Of them, 5 were full professors, 2 were associate professors, and 3 were assistant professors. They had spent a median of 18.5 years (range, 5-22 years) at the institution, and had a median $h$ index of 46 (range, 27-77). The top 10 men raised a median of $\$ 5,607.497 .24$ (range, $\$ 3,369.081 .14-\$ 29,507,783.50$ ) over a median of 726 gifts (range, 41-5,982); 8 were full professors and 2 were assistant professors. They had spent a median of 21 years (range, 7-39 years) at the institution, and their median $h$-index was 68.5 (range, 6-100).

\section{Discussion}

In this study, we found gender differences in likelihood of receiving PDs of every kind, including from individuals, corporations/foundations, and estates/trusts. Men were more likely to receive donations and raise more total funds. However, on multivariable analyses, senior academic rank and $h$-index were the only significant predictors of donation receipt and $h$-index was the only significant predictor of donation amount, suggesting that previously documented disparities in promotions and productivity could be a driver of the observed differences in PDs. ${ }^{5,8}$

Previous studies have shown the $h$-index metric's association with future productivity and NIH funding, as well as corroborate its association with academic rank in radiation oncology. ${ }^{13-15}$ Our study further adds to these data, suggesting its association with PD receipt. We found that $h$-index was the only factor associated with both PD receipt and donation amount. This finding potentially suggests that past productivity may increase the likelihood of philanthropic fundraising, even accounting for academic rank and years in practice.

In this study, men had nearly double the median $h$ index of women medical and radiation oncologists. This finding is in line with several other studies by researchers of various specialties that demonstrate gender differences in $h$-index. ${ }^{8,16-21}$ These disparities are likely multifactorial, with cited reasons including lack of mentorship and sponsorship, gender discrimination in the workplace, pregnancy and childrearing burdens, and more allocation of time to teaching and clinical work. ${ }^{22,23}$ At the same time, women face disparities in administrative, grant, and research support that are crucial for publication productivity, which may in turn affect chances of PD receipt. ${ }^{6,7,24}$ The $h$-index also does not reflect place on the authorship list, and "courtesy" authorship offers may be more likely to be extended to men. This metric does not capture selfcitation, which men have been shown to practice more frequently. ${ }^{19}$ Articles by women may, for example, be less likely to be cited than those by men for reasons that are unrelated to publication importance. Interestingly, some work does suggest that gender differences in $h$-index may be most prominent at junior levels but disappear when analyzing physicians of more senior academic rank..$^{8,18,20}$ This effect could possibly be related to delay in careers during childbearing and rearing of young children, or selection bias due to attrition of women from academia.

Multipronged strategies to support women and address gender discrimination at academic hospitals are crucial to improving productivity and philanthropic fundraising. Institutional efforts to support women at early career stages, including formal mentorship programs, robust family leave policies, onsite childcare, and work flexibility, could help address productivity barriers. ${ }^{21,25,26}$ Additionally, dedicated task forces and search committee 
A

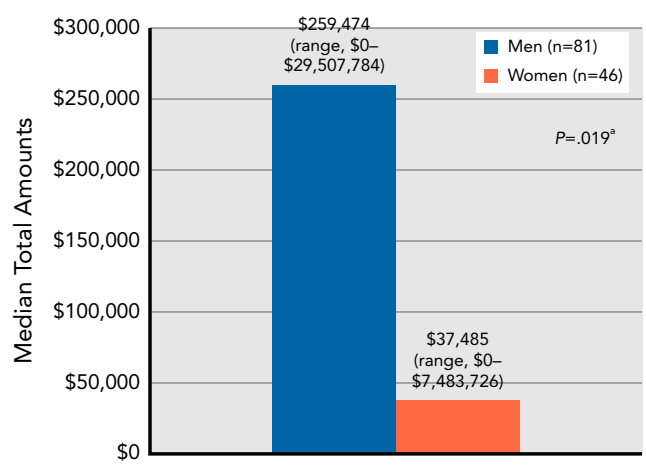

C

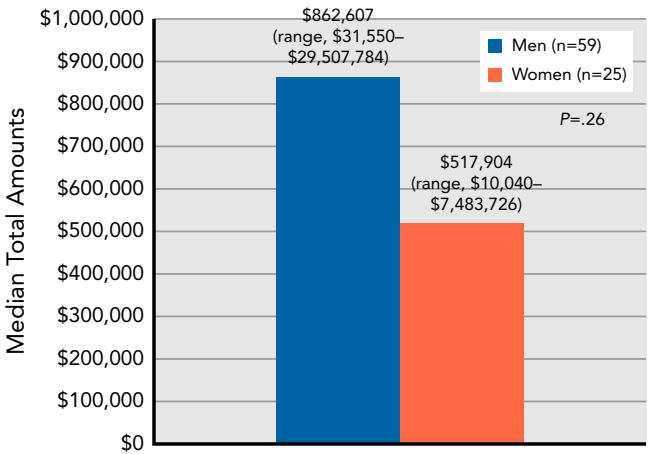

B

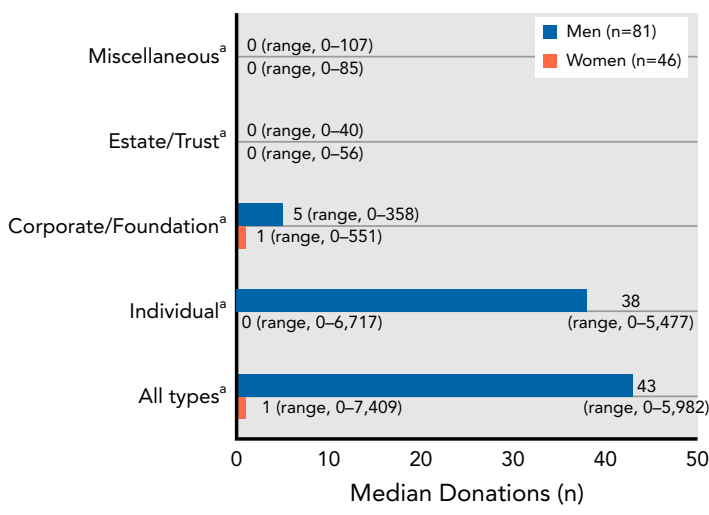

D

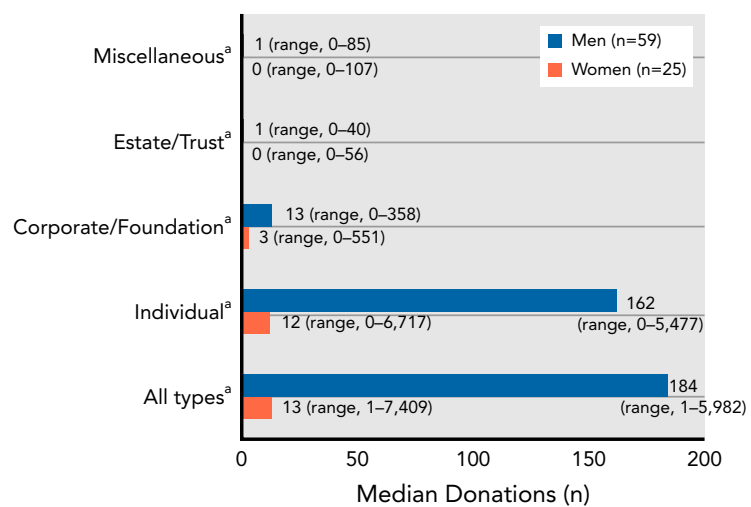

Figure 1. Median total amounts and numbers, by donation type, of philanthropic donations to male and female oncologists (A, B) for all physicians $(n=127)$ and $(C, D)$ in the subset of physicians with $\geq 1$ donation $(n=84)$.

${ }^{\text {a }}$ Statistical significance of comparison between 2 groups using Wilcoxon rank-sum test.

trainings can improve recruitment of women faculty to leadership positions and contribute to advocacy for equitable hiring practices and resources. ${ }^{8,25,26}$ Development offices could also promote the academic work of women physicians, as well as provide education to improve comfort with solicitation of PDs. Additionally, PDs could be distributed across departments, disease sites, or institutions, rather than going to individual physicians.

\begin{tabular}{|c|c|c|c|}
\hline Donation receipt & Odds Ratio & $95 \% \mathrm{Cl}$ & $P$ Value \\
\hline Gender (men vs women) & 1.14 & $0.42-3.08$ & .794 \\
\hline$h$-index (per unit change) & 1.09 & $1.04-1.15$ & $<.001$ \\
\hline Senior academic rank ${ }^{a}$ & 14.69 & $1.60-134.62$ & .002 \\
\hline Years at institution (per unit change) & 0.99 & $0.93-1.06$ & .836 \\
\hline Total 10-year donation amount ${ }^{b}$ & $\beta$ Coefficient & SE & $P$ Value \\
\hline Gender (men vs women) & 0.17 & 0.18 & .343 \\
\hline$h$-index (per unit change) & 0.04 & 0.01 & $<.001$ \\
\hline Senior academic rank ${ }^{a}$ & -0.08 & 0.20 & .682 \\
\hline Years at institution (per unit change) & -0.01 & 0.02 & .759 \\
\hline
\end{tabular}

Bold indicates statistically significant $P$ value.

${ }^{a}$ Full/Associate versus assistant/instructor professor levels.

${ }^{b}$ Logarithmic transformation. 


\section{Table 4. Factors Associated With PD Receipt and Total 10-Year Donation Amount in Subset of Medical Oncologists}

\begin{tabular}{|c|c|c|c|}
\hline Donation receipt & Odds Ratio & $95 \% \mathrm{Cl}$ & $P$ Value \\
\hline Gender (men vs women) & 1.11 & $0.38-3.23$ & .852 \\
\hline$h$-index (per unit change) & 1.09 & $1.04-1.15$ & $<.001$ \\
\hline Senior academic rank ${ }^{a}$ & 10.63 & $1.04-108.86$ & .015 \\
\hline Years at institution (per unit change) & 0.99 & $0.93-1.06$ & .806 \\
\hline Total 10-year donation amount ${ }^{b}$ & $\beta$ Coefficient & SE & $P$ Value \\
\hline Gender (men vs women) & 0.14 & 0.20 & .497 \\
\hline$h$-index (per unit change) & 0.04 & 0.01 & $<.001$ \\
\hline Senior academic rank ${ }^{a}$ & -0.04 & 0.23 & .873 \\
\hline Years at institution (per unit change) & 0.01 & 0.02 & .818 \\
\hline
\end{tabular}

Bold indicates statistically significant $P$ value.

Abbreviation: philanthropic donation.

${ }^{a}$ Full/Associate versus assistant/instructor professor levels.

${ }^{b}$ Logarithmic transformation.

Our results are limited because it is a small study, representative of a single institution, and there are likely other unaccounted covariables. Gender could also be associated with differences in patient volume, clinical patterns, and referrals, potentially providing men with more opportunities for contact with wealthier patients and solicitation of PDs. Additionally, although most gender-related disparities research discusses gender in binary terms, it exists on a spectrum, which our data do not reflect. In addition, use of the $h$-index to measure productivity has flaws and may not fully capture research productivity. The $h$-index also does not capture the clinical productivity of a physician, which might assist in relationship-building for philanthropic fundraising, and does not capture physician value.

Despite these limitations, our work is the first to quantitatively assess the relationship between productivity, gender, and PDs. Further research and focused interventions are needed to ensure that female physicians are equitable recipients of PDs, and to better understand relationships with gender-related disparities in academic productivity, promotions, and compensation.

\section{Conclusions}

In this study of philanthropic fundraising among medical and radiation oncologists at a large academic cancer center, we found significant gender disparities in likelihood of receiving PDs and total fundraising amount on unadjusted analyses. However, on multivariable analyses, $h$-index and academic rank were significantly associated with PDs, suggesting that gender disparities in promotions and productivity may contribute to these differences.

Submitted October 27, 2020; final revision received January 3, 2021; accepted for publication January 14, 2021

Author contributions: Study concept: Perni, Bitterman, Haas-Kogan, Tarbell, Parikh, Wo. Data curation: Perni, Bitterman. Formal analysis: Perni, Parikh, Wo. Investigation: Perni, Bitterman, Parikh, Wo. Methodology: Perni, Bitterman, Haas-Kogan, Tarbell, Parikh, Wo. Project administration: Perni. Resources: J. Ryan, Mitchell, Christensen, Daniels, Bloom, Hochberg, D. Ryan, Loeffler, Parikh, Wo. Supervision: Wo. Visualization: Perni, Silver. Writing-original draft Perni. Writing-review and editing: Bitterman, J. Ryan, Silver, Mitchell, Christensen, Daniels, Bloom, Hochberg, D. Ryan, Haas-Kogan, Loeffler, Tarbell, Parikh, Wo

Disclosures: Dr. Parikh has disclosed serving on a data safety monitoring board for Roche; receiving institutional research support from Novartis, Bristol Myers Squibb, PMV Pharma, Takeda, Plexxicon, and Puretech; serving as a scientific advisor for C2i; and serving on an advisory board for Eli Lilly, Pfizer and Checkmate Pharmaceuticals. The remaining authors have disclosed that they have not received any financial consideration from any person or organization to support the preparation, analysis, results, or discussion of this article.

Correspondence: Jennifer Wo, MD, Department of Radiation Oncology, Massachusetts General Hospital, 55 Fruit Street, Cox Building 3, Boston, MA 02214-2696. Email: jwo@mgh.harvard.edu; and

Aparna R. Parikh, MD, Department of Medicine, Division of Hematology/ Oncology, Massachusetts General Hospital, 50 Blossom Street BAR, Boston, MA 02114-2696. Email: aparna.parikh@mgh.harvard.edu

\section{References}

1. Dorsey ER, de Roulet J, Thompson JP, et al. Funding of US biomedical research, 2003-2008. JAMA 2010;303:137-143.

2. Collins ME, Rum SA, Sugarman J. Navigating the ethical boundaries of grateful patient fundraising. JAMA 2018;320:975-976.

3. Collins ME, Rum S, Wheeler J, et al. Ethical issues and recommendations in grateful patient fundraising and philanthropy. Acad Med 2018;93:1631-1637.

4. Wright $S M$, Wolfe $L$, Stewart R, et al. Ethical concerns related to grateful patient philanthropy: the physician's perspective. J Gen Intern Med 2013;28:645-651.

5. Carr PL, Raj A, Kaplan SE, et al. Gender differences in academic medicine: retention, rank, and leadership comparisons from the National Faculty Survey. Acad Med 2018;93:1694-1699.

6. Holliday E, Griffith KA, De Castro R, et al. Gender differences in resources and negotiation among highly motivated physician-scientists. J Gen Intern Med 2015;30:401-407

7. Jagsi R, Griffith KA, Stewart A, et al. Gender differences in the salaries of physician researchers. JAMA 2012;307:2410-2417. 
8. Holliday EB, Jagsi R, Wilson LD, et al. Gender differences in publication productivity, academic position, career duration, and funding among U.S academic radiation oncology faculty. Acad Med 2014;89:767-773.

9. Tringale KR, Marshall D, Mackey TK, et al. Types and distribution of payments from industry to physicians in 2015. JAMA 2017;317:1774-1784.

10. Eagly AH, Karau SJ. Role congruity theory of prejudice toward female leaders. Psychol Rev 2002;109:573-598.

11. Walter JK, Griffith KA, Jagsi R. Oncologists' experiences and attitudes about their role in philanthropy and soliciting donations from grateful patients. J Clin Oncol 2015;33:3796-3801.

12. Hirsch JE. An index to quantify an individual's scientific research output. Proc Natl Acad Sci USA 2005;102:16569-16572.

13. Rezek I, McDonald RJ, Kallmes DF. Is the $\mathrm{H}$-index predictive of greater $\mathrm{NIH}$ funding success among academic radiologists? Acad Radiol 2011;18: 1337-1340.

14. Zhang $C$, Murata $S$, Murata $M$, et al. Factors associated with increased academic productivity among US academic radiation oncology faculty. Pract Radiat Oncol 2017:7:e59-64.

15. Hirsch JE. Does the $\mathrm{H}$ index have predictive power? Proc Natl Acad Sci USA 2007:104:19193-19198.

16. Chauvin S, Mulsant BH, Sockalingam S, et al. Gender differences in research productivity among academic psychiatrists in Canada. Can J Psychiatry 2019;64:415-422.

17. Okafor S, Tibbetts K, Shah G, et al. Is the gender gap closing in otolaryngology subspecialties? An analysis of research productivity. Laryngoscope 2020:130:1144-1150.
18. Myers SP, Reitz KM, Wessel CB, et al. A systematic review of gender-based differences in Hirsch index among academic surgeons. J Surg Res 2019; 236:22-29.

19. Astegiano J, Sebastián-González E, Castanho CT. Unravelling the gender productivity gap in science: a meta-analytical review. R Soc Open Sci 2019; 6:181566.

20. Lopez SA, Svider PF, Misra P, et al. Gender differences in promotion and scholarly impact: an analysis of 1460 academic ophthalmologists. J Surg Educ 2014;71:851-859.

21. Eloy JA, Svider PF, Cherla DV, et al. Gender disparities in research productivity among 9952 academic physicians. Laryngoscope 2013;123:18651875.

22. Jagsi R, Guancial EA, Worobey CC, et al. The "gender gap" in authorship of academic medical literature-a 35-year perspective. N Engl J Med 2006 355:281-287

23. Patton EW, Griffith KA, Jones RD, et al. Differences in mentor-mentee sponsorship in male vs female recipients of National Institutes of Health grants. JAMA Intern Med 2017;177:580-582.

24. Warner ET, Carapinha R, Weber GM, et al. Gender differences in receipt of National Institutes of Health R01 grants among junior faculty at an academic medical center: the role of connectivity, rank, and research productivity. J Womens Health (Larchmt) 2017;26:1086-1093.

25. Carr PL, Gunn C, Raj A, et al. Recruitment, promotion, and retention of women in academic medicine: how institutions are addressing gender disparities. Womens Health Issues 2017;27:374-381.

26. Agrawal P, Madsen TE, Lall M, et al. Gender disparities in academic emergency medicine: strategies for the recruitment, retention, and promotion of women. AEM Educ Train 2019;4(Suppl 1):S67-74.

\section{RECORDED PRESENTATIONS}

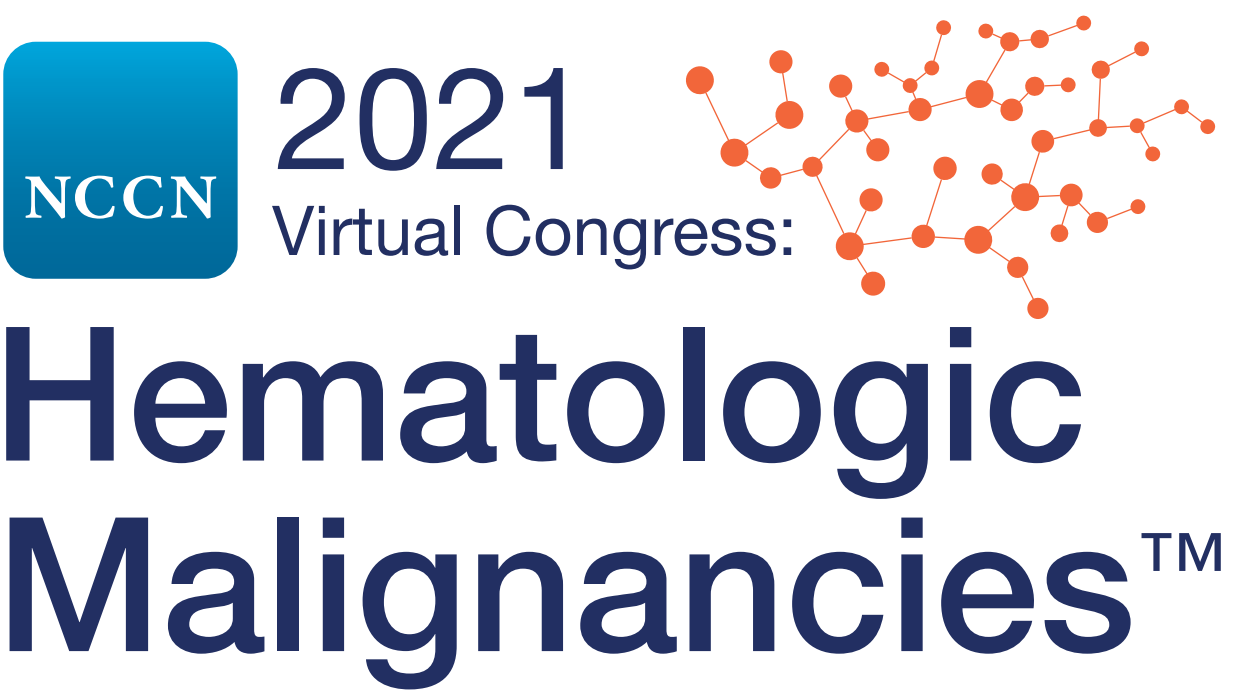

VIEW NOW: education.nccn.org/hem2021 